\title{
Estado e expansão do ensino superior privado no Brasil: \\ uma análise institucional dos anos de 1990
}

\section{State and expansion of private higher education in Brazil: an institutional approach from years of 1990}

\author{
Sandro Aparecido Gonçalves*
}

\begin{abstract}
RESUMO
Este artigo trata da expansão do ensino superior privado no Brasil, durante os anos de 1990, tendo como base as mudanças institucionais que envolveram o Estado no século XX, destacando sua crise nos anos de 1980, que culminaram na busca de um novo modelo na última década analisada. Merece ser enfatizado que ainda não há clareza das relações entre Estado e Sociedade, mesmo em meados do século XXI, posto que possui menor número de instrumentos de ação direta, não obteve redução significativa em seu tamanho, apresenta dificuldades nas operações regulatórias, mas mantém razoável interesse em se constituir como Estado de Bem-Estar. Nesse contexto, torna-se mais fácil o entendimento da expansão em voga, na medida em que se trata de um aspecto da mudança e não de um fenômeno isolado. Quanto à metodologia, foram realizadas 32 entrevistas semi-estruturadas e análise de autores que abordaram o assunto, cujas principais conclusões estão apresentadas no final do texto.

Palavras-chave: ensino superior privado; reforma do Estado; teoria institucional.
\end{abstract}

* Doutor em Administração pela EAESP-FGV-SP, Mestre em Administração pelo CEPPADUFPR.. Professor do PMDA - Universidade Positivo - E-mail: sag2@uol.com.br 


\begin{abstract}
This article deals with the expansion of the private higher education in Brazil in the 1990's based on the institutional changes involving the State in twentieth century, highlighting the crisis of the 1980's and culminating in the search for a new model in the last decade of analysis. It is worth pointing out that there is still no clarity concerning the relationship between State and Society, even in the twenty-first century. Given that the State has fewer instruments to direct action, it has not managed to reduce its size, has difficulty with regulatory operations and also has a reasonable interest in being constituted as the Welfare State. In this context, it becomes easier to understand the current expansion in that it is an aspect of change and not an isolated phenomenon. As a methodological approach, thirty-two semi-structured interviews were conducted, and others read authors who have dealt with the subject. The main conclusions are given in this text. Key words: private high school education, State transformation, institutional theory.
\end{abstract}

\title{
Perspectiva teórica
}

Um exame mais detalhado da relação que se estabelece entre o ambiente e os atores sociais é oferecido pelos institucionalistas (de vertente sociológica), conforme Machado-da-Silva e Fonseca:

De acordo com os institucionalistas, as organizações estão inseridas em um ambiente constituído de regras, crenças e valores, criados e consolidados por meio da interação social. Nesse sentido, a sua sobrevivência depende da capacidade de atendimento a orientações coletivamente compartilhadas, cuja permanente sustentação contribui para o êxito das estratégias implementadas e, por conseguinte, para o pleno funcionamento interno. Assim, diante das mesmas prescrições ambientais, as organizações também competem pelo alcance da legitimidade institucional, o que torna suas práticas cada vez mais homogêneas, ou isomórficas. (MACHADO-DASILVA e FONSECA, 1996, p. 213). 
Esse isomorfismo, ou processo de modificação organizacional rumo à compatibilidade com as características ambientais, segundo Machado-da-Silva e Fonseca (1993, p. 148), decorre da influência de mecanismos coercitivos, miméticos e normativos, que reduzem a variedade e a instabilidade dos arranjos estruturais vigentes em um campo institucional.

De acordo com DiMaggio e Powell (1983), o isomorfismo coercitivo resulta de pressões formais e informais exercidas por uma organização sobre outra que se encontra em condição de dependência. Em face de ambientes legal e político comuns, a ação organizacional pode constituir-se como resposta a diretrizes governamentais. A imposição de regras e procedimentos padronizados pode ocorrer, também, a partir das relações de autoridade, como no caso da adoção, por parte de uma subsidiária, de procedimentos operacionais compatíveis com a política ditada pela empresa matriz.

O segundo mecanismo de mudança isomórfica é mimético e fundamenta-se na adoção, por parte de uma organização, de procedimentos e arranjos estruturais implementados por outras organizações, a fim de reduzir a incerteza ocasionada por problemas tecnológicos, objetivos conflitantes e exigências institucionais. Modelos de ação podem ser assim incorporados indiretamente, mediante a transferência e a rotatividade de empregados, ou diretamente, por meio, por exemplo, da contratação de firmas de consultoria. Organizações também podem apresentar um comportamento mimético, ao verificar o sucesso de outras organizações atuantes no mesmo ramo de atividades.

DiMaggio e Powell (1983) sugerem, ainda, que o grau de profissionalização é, talvez, o fator mais importante como mecanismo normativo que cumpre considerar para o entendimento das pressões acarretadas pelo isomorfismo ambiental. A profissionalização envolve o compartilhamento de um conjunto de normas e rotinas de trabalho pelos membros de determinada ocupação. $\mathrm{O}$ isomorfismo normativo conduz a formas comuns de interpretação e de ação, institucionalizadas em subculturas ocupacionais.

A influência de cada um desses mecanismos institucionais na ação organizacional pode ocorrer independentemente de qualquer evidência aparente de acréscimo na eficiência interna. $\mathrm{O}$ isomorfismo, afinal, é um mecanismo vantajoso para as organizações, já que a similaridade facilita as transações interorganizacionais e favorece o seu funcionamento interno pela incorporação de regras socialmente aceitas (DiMAGGIO e POWELL, 1983; MEYER e ROWAN, 1983). 
Esse modelar da realidade social ocorre em primeiro momento pelo hábito, que é, enquanto processo, condição de toda institucionalização. Na institucionalização, segundo Berger e Luckmann (1967, p. 57), ocorre que sempre há uma tipificação recíproca de ações habituais por tipos de atores, que produzem instituições cujas ações do tipo X deverão ser executadas de maneiras específicas e por atores do tipo X. Dessa forma, estabelecidas, as instituições, pelo simples fato de existirem, controlam a conduta humana, ao conduzirem, por meio de seus padrões, para uma direção em oposição a muitas outras possíveis.

Nessa medida, a história não tem princípio, tem origem; não tem destino, é probabilística. A sociedade organizacional se apresenta como uma rede de organizações às quais os atores individuais se vinculam e por meio das quais agem e produzem o resultado de suas ações. $\mathrm{O}$ institucionalismo é uma teoria de médio alcance, justamente por se concentrar nesse espectro de fenômenos.

Em adição, Emirbayer e Goodwin (1994) entendem que uma rede social é uma entre muitas possibilidades para representar as relações sociais de um conteúdo específico, como a comunicação, o poder, o afeto, as trocas ou os incentivos econômicos que vinculam os atores dentro de uma ampla estrutura social (ou redes de redes). Nessa medida, a unidade de análise não precisa ser uma pessoa, mas pode ser um grupo, uma organização ou uma sociedade inteira, isto é, uma entidade conectada por meio de uma rede com outras entidades. Ressalva-se, no entanto, para fins do conceito de campo organizacional, que os atores sociais não precisam realmente interagir na rede, sendo suficiente que sejam, em alguma medida, influenciados para que a relação social seja considerada. (DiMAGGIO e POWELL, 1983).

Campo organizacional é definido como organizações que, em seu conjunto, constituem uma área de reconhecimento da vida institucional: os principais fornecedores, as fontes de recursos, os consumidores, as agências reguladoras e outras organizações que produzem produtos e serviços similares. Esta definição, cabe frisar, tem sua origem em estudos dos setores industriais (manufatureiros). Contudo, o conceito de campo organizacional é mais abrangente do que isso; a noção de campo denota a existência de uma comunidade de organizações que compartilham um sistema de significados comuns e cujos participantes interagem mais freqüentemente entre si do que com outros atores sociais fora do campo. O campo organizacional visa explicar a convergência das formas e práticas organizacionais, orientadas pela legitimidade, que é, por sua vez, produto dos isomorfismos que ocorrem em seu interior. 
Dessa forma, segundo DiMaggio e Powell (1983), o processo de definição ou reestruturação do campo consiste em quatro elementos. O primeiro é o aumento da amplitude da interação entre as organizações do campo; o segundo é o surgimento de estruturas de dominação e padrões de coalizão interorganizacionais claramente definidos; o terceiro refere-se ao aumento na carga de informação com a qual as organizações dentro de um campo devem lidar; por fim, a formação de uma consciência mútua entre os participantes de um grupo de organizações que envolvem um negócio comum; no caso específico, o ensino superior privado.

\title{
Propostas e mudanças do Estado brasileiro
}

\author{
Segundo Bresser Pereira (1996, p. 70),
}

[...] no passado, dos anos 30 aos anos 70, o Estado desempenhou um papel decisivo na promoção do crescimento econômico; nos anos 80 , devido à crise fiscal, o Estado perdeu sua capacidade de promover o crescimento econômico e tornou-se um obstáculo fundamental para isso.

Para o autor, os anos de 1980 ficaram muito distantes do que foram as décadas anteriores; a dívida interna do Estado encontrava-se em 48,1\% do PIB do ano de 1985.

Na opinião de Fiori (1989), a crise do final dos anos de 1970 comprometeu a capacidade gestora do Estado. Isso explica porque os mecanismos estatais de decisão e sustentação de políticas de longo prazo ficaram atrofiados. Em adição, o investimento, baseado no financiamento externo e estatal, com gerência direta do Estado ou com subsídios ofertados para a ocorrência do investimento privado, entrou em crise quando, em 1982, houve uma quebra no fluxo de financiamento externo líquido. (BRESSER PEREIRA, 1996).

Para Gonçalves (1998), crise econômica e desencontros políticos e sociais marcaram a década de 1980 na América Latina. Em concordância, Bresser Pereira (1996), aponta a estagnação e altas taxas de inflação como fatores determinantes na trajetória da economia brasileira nessa década, como se observa na Tabela 1. 
GONÇALVES, S. A. Estado e expansão do ensino superior privado no Brasil...

TABELA 1 - RESULTADOS DO PADRÃO DE DESENVOLVIMENTO BRASILEIRO (1950-1980)

\begin{tabular}{lccc}
\hline $\begin{array}{c}\text { TAXA DE CRESCIMENTO } \\
(\%)\end{array}$ & $\begin{array}{c}\text { PERÍODO BASE } \\
(1950-80)\end{array}$ & $\begin{array}{c}\text { PERÍODO DE CRISE } \\
(1980-92)\end{array}$ & $\begin{array}{c}\text { PERÍODO } \\
\text { PÓS-CRISE } \\
(1992-98)\end{array}$ \\
\hline PIB & 7,0 & 1,3 & 1,8 \\
\hline PIB Per Capita & 4,1 & $-0,7$ & 0,1 \\
\hline Acumulação de capital & 9,8 & 2,7 & 2,6 \\
\hline Produtividade do trabalho * & 3,9 & 1,4 & 0,6 \\
\hline
\end{tabular}

Fonte: adaptado de HOFMAN (1999)

* PIB dividido pela população economicamente ativa.

No caso brasileiro, a interferência estatal no mercado implicou em distorções crescentes na sobrevivência do Estado, que culminaram em uma situação insustentável na década de 1990. Nos anos de 1980, a crise no Estado deixa evidente a fragilidade do modelo econômico em vigência, qual seja, o nacionalismo econômico, a substituição de importações, o emprego de capitais externos para alavancar o crescimento e o Estado como produtor direto de bens e serviços. No Brasil, o peso da presença do Estado na economia tornou necessária uma reforma ou reconstrução deste pois já não conseguia atender às demandas a ele dirigidas, principalmente as sociais. A reforma passou a ser exigida pelos cidadãos que viam, então, frustradas suas demandas e expectativas (MINISTÉRIO DO PLANEJAMENTO, 1995).

Com as demandas sociais sendo as mais prementes, pode-se dizer que era inadiável, além de outras prioridades, a inovação dos instrumentos de política social e a reforma do aparelho do Estado. Essa reforma aumentaria a governança, ou seja, a capacidade de implementar eficientemente políticas públicas. Nota-se aqui o termo "aparelho" do Estado.

Entende-se por aparelho do Estado a administração pública em sentido amplo, ou seja, a estrutura organizacional do Estado, em seus três poderes (Executivo, Legislativo e Judiciário) e três níveis (União, Estados-membros e Municípios). O aparelho do Estado é constituído pelo governo, isto é, pela cúpula dirigente nos Três Poderes, por um corpo de funcionários, e pela força militar. (MINISTÉRIO DO PLANEJAMENTO, 1995) 
A idéia principal do Plano Diretor de Reforma do Estado, do Ministério do Planejamento do Brasil, é de que o Estado reduza o seu papel de executor ou prestador direto de serviços, mantendo-se, no entanto, no papel de regulador ou provedor destes. Há um destaque para a prestação de serviços sociais como saúde e educação, essenciais para o desenvolvimento. O Estado continuará a subsidiar tais serviços e, em uma nova perspectiva, exercerá as funções de regulação e coordenação, principalmente em nível federal.

O modelo liberal de economia, vivenciado atualmente, foi instituído em âmbito internacional entre as décadas de 1970 e 1980. Segundo Dupas (1999), o vácuo teórico e a incapacidade de gestão dos estados nacionais, situações oriundas da crise pós-keynesiana, cederam espaço para os defensores do Estado Mínimo. Para Sunkel (1999), a democracia liberal se impôs na arena política, bem como o sistema de mercado, em sua forma neoliberal. O domínio do neoliberalismo, conforme Sachs (1999), está amparado pelo enfraquecimento de velhos modelos econômicos.

O "socialismo real" caiu por terra, por razões essencialmente políticas. A ausência de transparência e de instituições democráticas que permitissem um controle social eficiente do funcionamento do Estado resultou no surgimento de formas de estatismo patológicas ou de visão estreita, de clientelismo e de patrimonialismo, com efeitos devastadores sobre a eficácia do sistema econômico. (SACHS, 1999, p. 198)

Diniz (1997) entende que com o padrão de expansão do sistema capitalista abalado, o Estado passou a ser encarado como o principal entrave ao desencadeamento de um novo ciclo de crescimento. Segundo Castor (2004), no Brasil, o Estado gozou, por séculos, de poderes extraordinários, que lhe permitiram cumprir um papel central no processo de formação nacional. A estratégia intervencionista adotada em quase todo o século passado baseava-se em três instrumentos:

[...] uma ação política de defesa e fortalecimento da empresa nacional; a criação de um grupo de entidades de fomento econômico, encarregado de formular e executar políticas públicas protecionistas e regulatórias; e, por último, a criação e o fortalecimento de empresas públicas para atuar diretamente nos setores considerados prioritários. (CASTOR, 2004, p. 73) 
É neste sentido que Diniz (1997) afirma que a via de modernização industrial conduzida pelo Estado entre os anos de 1930 e 1970 perdeu condições de viabilidade. No entanto, observava-se nos anos de 1990 o revigoramento dos princípios do mercado e a reafirmação dos valores neoliberais.

A reforma do Estado é um tema explorado por Bresser Pereira (1997), que defende a implementação de uma administração pública gerencial. É necessária, pois teria papel decisivo na possível entrada de um novo modelo de desenvolvimento. Fiori (1991) concorda que há uma verdadeira crise orgânica do Estado, que, para ser solucionada, deve passar por uma redefinição de compromissos entre os atores sociais e econômicos.

Conforme Pinto (2004), o Estado e a administração pública não conseguem cumprir sua função de investimento. As despesas da administração pública são oneradas pela necessidade de manutenção de um aparelho estatal inchado, de custo muito elevado e ineficiente quanto às suas atribuições.

A década de 1980 foi marcada pelo final da ditadura militar, intervenção estatal e bases do modelo desenvolvimentista:

No final dos anos 80 o Brasil ainda mantinha todos os mecanismos de intervenção estatal. Porém, o Estado brasileiro vinha perdendo a sua capacidade de determinar o ciclo econômico devido à crise fiscal. $\mathrm{O}$ grande problema emergencial era uma inflação elevada que concentrava as atenções da política econômica. (MANTEGA, 2001a, p. 3)

A ascensão do neoliberalismo provocou uma série de transformações em diversos países ao redor do mundo. Em 1989, no International Institute of Economy, funcionários do governo dos EUA, dos organismos internacionais e economistas latino-americanos discutiram um conjunto de reformas essenciais para que a América Latina superasse a crise econômica e retomasse o caminho do crescimento (CANDELORI, 2002).

Williamson (1992) chamou as principais diretrizes elaboradas neste encontro de Consenso de Washington. Os pensamentos estavam sintetizados em um conjunto de nove medidas técnicas para uma recuperação econômica dos países latino-americanos. Em resumo eram as decisões julgadas mais apropriadas a serem tomadas pelos países chamados em desenvolvimento, incluídos os da América Latina (GIAMBIAGI e MOREIRA, 2000): 1) redução dos déficits orçamentários e do déficit operacional (déficit, descontada apenas a parte dos juros que compensam a inflação) a não mais de $2 \%$ do PIB; 2) prioridade dos gastos públicos, redirecionando os gastos para áreas negligenciadas com alto 
retorno econômico e potencial para melhorar a distribuição de renda, como saúde, educação e infra-estrutura; 3) aumento da base tributária e corte nas taxas tributárias marginais; 4) liberalização de financiamento, cujo objetivo final era uma taxa de juros determinada pelo mercado; 5) taxa de câmbio fixada em nível suficiente para induzir o rápido crescimento das exportações; 6) liberalização do comércio: restrições quantitativas deveriam ser substituídas por restrições tarifárias, sendo recomendável a desaceleração do processo quando as condições macroeconômicas fossem adversas; 7) investimento externo direto: barreiras impeditivas de entrada de firmas estrangeiras deveriam ser abolidas; 8) privatização de empresas estatais; 9) extinção de regulamentações que impedissem a entrada de novas firmas ou que restringissem a competição, assegurando que toda a regulamentação fosse justificada por critérios técnicos.

Essas medidas, consideradas neoliberais, foram aplicadas no início dos anos de 1980 no governo de Margareth Thatcher (Inglaterra) e de Ronald Reagan (EUA) com o objetivo de reduzir o tamanho do Estado por meio, principalmente, da privatização das empresas estatais, flexibilização da legislação trabalhista, redução da carga fiscal e abertura comercial (CANDELORI, 2002), e serviram de inspiração para o Consenso de Washington. No entanto, cabe frisar que eram recomendações gerais; ou seja, tais medidas poderiam se adequar melhor a alguns países do que a outros (GIAMBIAGI e MOREIRA, 2000).

O Brasil cumpriu com maior ou menor rigor toda a pauta do Consenso de Washington. No entanto, após a adoção de algumas das medidas prescritas, encontrase em uma situação em que o Estado está enfraquecido e subordinado ao mercado. Ainda assim, não consegue cumprir a agenda social.

Durante os anos de 1990, houve planos com o intuito de estabilizar a inflação, porém infrutíferos. Somente em 1994, no governo Itamar Franco, implementou-se o Plano Real, que derrubou os elevados níveis de inflação. Porém, não foi concebido apenas para a estabilização da inflação. Ele contemplava também um projeto de reformas e profundas modificações, que iriam alterar substancialmente a natureza e o papel do Estado brasileiro. Segundo Mantega (2001b), o plano colocaria em evidência o novo Estado liberal, acabando com as bases de sustentação do Estado desenvolvimentista até então existente.

Ainda nos anos de 1990, o governo Fernando Henrique Cardoso, seguindo as mudanças propostas, deu início ao processo de desestatização do aparelho do Estado brasileiro. Para Mantega (2001a, p.27), “os princípios básicos professados por essa nova doutrina eram a desregulação do Estado, a privatização e a abertura comercial".

Diniz (1997) evoca que a necessidade de reformar o Estado apareceu também com a ascensão de países de posição estratégica no jogo de poder mundial (Estados Unidos, Inglaterra e Canadá), quando as condições foram criadas para o diagnóstico neoliberal. 
As privatizações brasileiras tinham por objetivo "[...] melhorar as contas públicas uma vez que as receitas obtidas pelo erário público serviriam para abater dívidas preexistentes". Porém, o resultado das privatizações não foi o esperado, pois " [...] as privatizações não tiveram nenhum grande impacto na dívida interna e ainda por cima podem agravar o passivo externo após breve alívio" (MANTEGA, 2001a, p.29-30).

Mantega (2001a) conclui em seu estudo que a década de 1990 foi o marco da transição do Estado desenvolvimentista para o modelo de inspiração neoliberal ${ }^{1}$, e que os principais mecanismos de intervenção estatal, utilizados no Brasil entre 1930 e 1980, foram desativados em prol do novo modelo econômico ora estabelecido por Fernando Henrique Cardoso; que em linhas gerais tem sido mantido pelo governo de Luiz Inácio Lula da Silva.

\section{Evolução do ensino superior privado no contexto de mudança do Estado}

Nas considerações a serem feitas sobre o ensino superior privado no Brasil, pelo menos dois padrões institucionais podem ser identificados. O primeiro seria uma explicação social-democrata por meio da qual a expansão do ensino superior utilizando-se de recursos privados e suporte, via subsidios, proporcionados pelo Estado, representaria uma forma de permitir a ascensão social e o aumento do nível de educação, sem o desvio de recursos públicos de seu foco prioritário, mais precário (em relação à capacidade de atendimento da demanda), que é o ensino fundamental e médio. Nessa perspectiva, os dados podem ser interpretados como uma escolha de prioridades diante da escassez de recursos. Como diversos autores sustentam, entre eles Sampaio (2000), trata-se, então, de um investimento de longo prazo baseado nas gerações mais novas.

${ }^{1}$ Em 1997, o setor da indústria extrativa mineral foi liberado para o capital estrangeiro. Foram criadas agências reguladoras, a Agência Nacional de Telecomunicações Anatel, a Agência Nacional de Energia Elétrica Aneel e a Agência Nacional de Petróleo - Anp. Para Castor (2004), elas foram criadas de forma acelerada, o que acabou por introduzir novas agências reguladoras que até os dias atuais encontram-se em estado de pré-pubescência institucional, procurando se afirmar e implantar uma prática regulatória independente de pressões políticas, como se pôde notar na crise política envolvendo a Agência Nacional de Aviação Civil (ANAC) durante a crise do setor aéreo de 2007. Destaca-se que essa forma regulatória, por agências, é típica da tese de Estado Mínimo. 
Contudo, na segunda posição, o argumento central é de que o Estado brasileiro, via seus mecanismos de intervenção e controle, aderiu à proposta chamada neoliberal, que claramente foi percebida em várias ações públicas ao longo dos anos de 1990. Nessa medida, a expansão privada do ensino superior seria apenas mais um reflexo dessa adesão, constituindo-se em uma saída privada para problemas públicos.

Neste artigo, nota-se a opção por esta última perspectiva, contudo, não por pura convicção do autor, que entende que os anos de 1990 foram mais complexos, combinando elementos de um Estado de bem-estar, com a manutenção e até mesmo a ampliação de serviços públicos, a despeito das críticas quanto à necessidade de melhorias conjugada com a visível retirada do Estado como empreendedor. Some-se a isso o aprendizado democrático em curso, e é possível observar um conjunto de ações, que se de um lado não permitem afirmações categóricas sobre o novo modelo de Estado emergente, também não podem ser reducionistas a ponto de classificá-lo como modelo neoliberal.

Porém, a opção que privilegia a chamada onda neoliberal foi feita a partir da opinião manifestada pelos 32 entrevistados ${ }^{2}$ (proprietários, diretores e coordenadores) que atuam na área de ensino privado em Curitiba-PR e representam 32 escolas privadas ${ }^{3}$, que assim a concebem - o que é pelo menos uma curiosidade a ser destacada, uma vez que o neoliberalismo denunciado foi justamente o que permitiu o surgimento dessas instituições de ensino superior. Dessa forma, e somente nessa medida, que conjugado com os autores citados e dados do MEC, parece constituir o movimento institucional predominante.

Para Coelho (2004), o documento do Ministério da Educação, que reafirma princípios e consolida diretrizes da reforma da educação superior, apresentado em agosto de 2004, com vistas à formulação de uma lei orgânica da educação superior, define a instituição pública como modelo de referência para a expansão do sistema. O Programa Universidade Para Todos, Prouni, instituído por medida provisória em vigor a partir de dezembro de 2004 e regulamentado pela Lei 11.096 em janeiro de 2005, antecipou-se à reforma que mudou o eixo de expansão para as instituições privadas.

Embora o argumento principal do Prouni seja a democratização do ensino superior, o programa fere a concepção da reforma, cujo modelo de referência é a

${ }^{2}$ Para maior detalhamento metodológico das razões da escolha, consultar a tese de Gonçalves (2006).

${ }^{3}$ Ainda que pertençam a um único município, as escolas e seus representantes estão imersos em um campo organizacional maior, participando de debates no MEC, na Secretaria de Ensino Superior, Inep, Associação de Mantenedores de instituições de ensino privadas, cujo núcleo comum das entrevistas representa mais do que uma opinião local, espelhando, em boa medida, o que vem ocorrendo nos grandes centros; destacam-se ainda que parte das escolas ou tem filiais fora de Curitiba, ou são filiais ou conveniadas com outras, tanto dentro quanto fora do Paraná. 
instituição pública, e deixa de cobrar das instituições privadas volume considerável de impostos, que poderiam ser destinados ao setor público educacional. A rigor, pode-se dizer que amplia o modelo anterior do Fundo de Financiamento ao Estudante do Ensino Superior - Fies.

Trindade (2004) entende que, de um lado, há massificação das instituições públicas nos países hispano-americanos; de outro, há privatização crescente da educação superior, da qual o Brasil é o exemplo extremo, com 75\% das matrículas nas instituições privadas. Na América do Sul, as instituições públicas são hegemônicas no campo da educação superior, salvo no Brasil, Chile e Colômbia, onde a privatização é dominante. Gazzola (2006) ressalta que o Brasil é hoje o sétimo país no mundo em presença de sistema privado de educação superior. Há, então, que regular, cobrando qualidade, por meio de instrumentos de autorização, credenciamento e recredenciamento, e avaliações de desempenho.

\begin{abstract}
A maior dificuldade consiste na reunião do corpo docente, porque um dos requisitos que compõem o procedimento de Autorização é a titulação e aderência dos professores às disciplinas que lecionam. Como existe um limite para docentes com título de bacharel ou especialista, acontece duas coisas, o empréstimo de títulos, uma vez que o professor que assinou o termo de compromisso não é necessariamente o que vai lecionar. Por meio de uma rede de contatos é possível rapidamente reunir um grupo de mestres e a formação acelerada de mestres, para atender à necessidade crescente e urgente de docentes titulados. (entrevista 28)
\end{abstract}

Os setores mais conservadores ${ }^{4}$ que promoveram de 1995 a 2002 o crescimento desenfreado do ensino privado, sem o menor controle da qualidade da educação brasileira, preocupados com as regras de mercado, criticam de forma ferrenha essa idéia de promover o ensino superior com real qualidade no nosso país (GAVIÃO, 2005).

A amplitude do acesso é inadequada: menos de $12 \%$ dos alunos em idade adequada estão matriculados no ensino superior. O que é pouco quando comparado com outros países da região (aArgentina, 41\%; o Peru, 40\%; o Uruguai, 30\%; a Venezuela, $29 \%$, e o Chile, 27\%), e aos países que compõem a Organization for Economic Cooperation and Development - OECD, com média de 49\% (WORD BANK ANNUAL $R E P O R T, 1995)$. Simplesmente dobrando as vagas ofertadas, contudo, não se dobraria a taxa de cobertura, devido ao inchaço demográfico dos jovens brasileiros que buscam alcançar as universidades. Em adição, a taxa de graduação dos egressos do

${ }^{4}$ Empresários do setor de Ensino Médio e outros atores mais acostumados, ou propensos, às teses liberais do capitalismo americano. 
ensino médio está recuando, relativamente ao aumento da oferta de vagas no ensino superior; abrindo espaço para os mais velhos, trabalhadores e aqueles que buscam uma segunda graduação.

Havia algumas pesquisas do final da década de 1980 que indicavam um déficit no número de escolas de nível superior no país; havia indicadores da ordem de 10 a $15 \%$ de crescimento anual de ingressos no ensino superior, do qual se poderia participar com crescimento razoável; a política governamental facilitou muito pois antes era necessário fazer carta consulta, mas nos anos recentes o marco regulatório se afrouxou bastante, (entrevista 5)

Aquela análise, acerca da amplitude do acesso, foi produzida com vistas a proporcionar informações práticas aos responsáveis por políticas, praticantes e o staff operacional do Word Bank, para propiciar um contexto e um guia aos esforços promovidos pela participação do setor privado. Esses documentos delimitam as principais restrições feitas ao setor privado.

As várias restrições ao desenvolvimento são analisadas, principalmente pelo $\mathrm{MEC}$, reformas ${ }^{5}$ são discutidas e os tons apropriados de intervenção são indicadores fortes para restrições ao setor privado e sua margem de expansão no setor social: 1) restrições ideológicas e preservação dos bens públicos e da ética nos mercados; 2) interesses arraigados que fazem com que se sinta que o poder será ameaçado pela competição, o que inclui pessoal de apoio, sindicatos, estudantes e facções políticas; 3 ) instabilidade macroeconômica, políticas impeditivas aos mercados. A introdução da participação privada cria fortes relações entre o ambiente e os setores sociais, e a capacidade e transparência da ação pública também têm grande impacto na escala e foco da participação privada; 4) restrições legais que criam desincentivos à entrada de novos atores do setor privado; 5) regulamentações demasiadamente restritivas para supervisão em monitoramento das operações do setor privado; 6) os mecanismos de fundos públicos e as restrições e a diversificação desses.

${ }^{5} \mathrm{O}$ que considera também quatro áreas críticas de intervenção: 1) entrada, no primeiro momento são necessárias políticas que permitam que o setor privado se estabeleça; 2) preço, as instituições sociais devem ampliar a base de captação de fundos, além do mero esforço para a cobrança de taxas dos usuários; 3) objetivos, garantir o acesso igualitário universal, com subsídios do Estado para aqueles que não tenham condições de pagamento; 4) regulação, por fim, é relevante para a qualidade do estabelecimento um forte e efetivo arcabouço normativo para avaliar a performance e monitorar o padrão. 
Existe forte mentalidade dos entrevistados, no que se refere aos custos elevados nos setores como saúde e ensino superior. O retorno social dos investimentos ${ }^{6}$ em educação é mais alto na educação fundamental e declina no sentido do ensino superior, em função da menor participação desse nível. No setor privado também declina na mesma direção; contudo o retorno social do ensino privado é maior no ensino superior do que no básico.

Uma questão que precisa ser levada em consideração é o custo, em relação aos cursos de período integral, como medicina e engenharia, os cursos de meio período, particularmente os noturnos, são muito mais baratos, dependendo basicamente de salas de aula e de uma biblioteca. (entrevista 3)

O que houve foi o reajuste das mensalidades, com certa dificuldade mas não a ponto de impedir o repasse dos custos. Talvez, em boa parte isso se deva à relutância em reduzir os preços diante da imagem negativa que a escola pode sofrer publicamente, por exemplo afirmações de que a escola está quebrando ou de que a qualidade será reduzida. (entrevista 8)

Tem se observado uma guerra de preços disfarçada na forma de descontos para pagamentos em dia ou antecipados. Além disso, os sindicatos patronais pretendem forçar uma redução nos valores das horas-aula. Outra tendência é a preferência pela contratação de mestres, ao invés de doutores, que são mais caros. Tem muitos casos de professores que omitem seu título de doutor para poderem continuar trabalhando. (entrevista 10)

O Ministério da Educação e Cultura e o Instituto Nacional de Estudos e Pesquisas Educacionais, são como fontes de burocracias que inevitavelmente devem ser cumpridas, porém não são órgãos dos quais emana força motriz para a melhora na qualidade do ensino, excetuando-se o fato de que suas auditorias são capazes de promover aperfeiçoamento na infra-estrutura das instituições. Fora isso, são mais como empecilhos do que suporte ao ensino superior. (entrevista 12)

De fato, quando se observa o Gráfico 1, que representa o crescimento do ensino fundamental e médio no Brasil, nota-se um aumento significativo, a partir de 1996, passando de 35 milhões de alunos para quase 46 milhões em 2002, o que deixa claro que a orientação proposta pelo Consenso de Washington e pela proposta de Bresser Pereira para a reforma do aparelho estatal provocou impacto por meio da Lei de Diretrizes e Bases da Educação Nacional - LDB, promulgada em 1996.

${ }^{6}$ Simplesmente por alcançar um número maior de pessoas, seja no sentido de incluir socialmente crianças e jovens, seja no sentido econômico, para a geração de mão-de-obra cuja qualificação pode ser dada na prática sem exigências de maior grau de instrução. 
GRÁFICO 1: CRESCIMENTO DAS MATRÍCULAS NO ENSINO FUNDAMENTAL E MÉDIO NO BRASIL

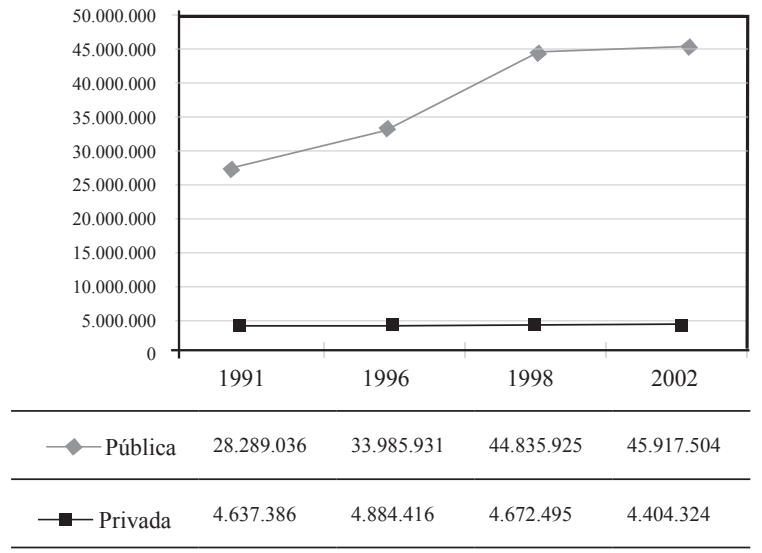

Fonte: Anuários Estatísticos do MEC

Quanto ao ensino superior, é possível sustentar a tese de que os recursos públicos foram maciçamente destinados ao ensino fundamental e médio em detrimento do ensino superior, a partir da análise feita por Bresser Pereira (1996), tanto como autor, quanto como ator, na medida em que foi Ministro da Reforma do Estado.

Em seu entendimento sobre o ensino superior, a forma de propriedade deve ser pública mas não estatal, o que ocorre até hoje por meio de concessões e fiscalização do MEC. Além disso, sua forma de administração é privada, por meio de concessão, tratada sob o rótulo de publicização, como se pode observar na figura 1.

Conjugado com o relatório do Word Bank (1995) sobre a baixa taxa de acesso ao ensino superior no Brasil quando comparado a outros países da América do Sul, a estratégia de reforma do aparelho público implicou, no caso brasileiro, em significativo aumento da participação privada no ensino superior, com inflexão visível após 1998, como pode ser observado no gráfico 2 . 
GONÇALVES, S. A. Estado e expansão do ensino superior privado no Brasil...

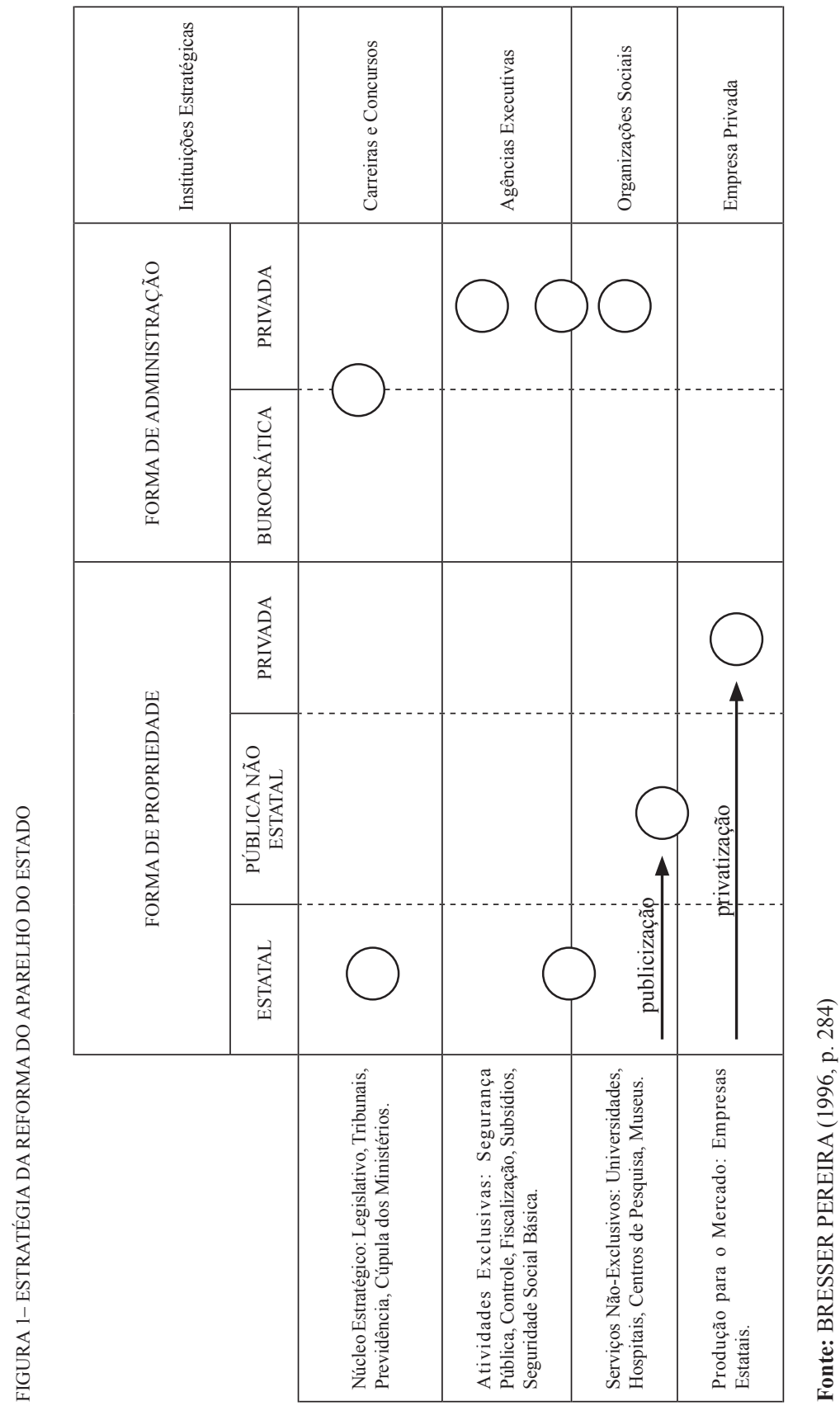


GRÁFICO 2- CRESCIMENTO DAS MATRÍCULAS NO ENSINO SUPERIOR NO BRASIL

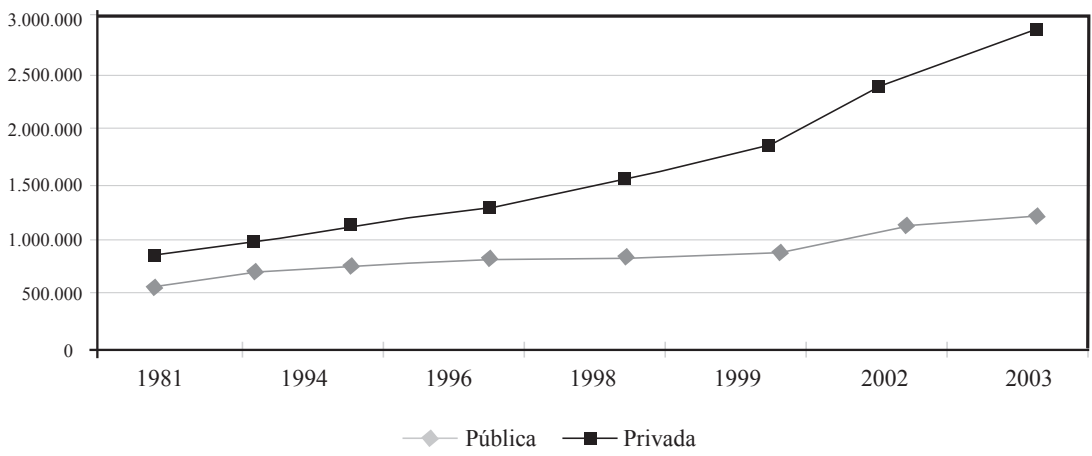

Fonte: Anuários Estatísticos do MEC

\section{Considerações finais}

As pressões institucionais que configuraram a expansão do ensino superior privado no Brasil são de natureza mais ampla e profunda, pois fazem parte do próprio processo de reformulação do Estado, que envolve o esgotamento do modelo de crescimento, na relação com a economia, e de atendimento das demandas sociais, na relação com a sociedade. Indo além, a expansão não foi exatamente fruto de um pensamento brasileiro acerca de sua realidade, mas resultado de forte intervenção de organismos internacionais, com destaque para o governo americano e o Word Bank; e não se restringiu ao Brasil, direcionando-se à América Latina em geral, com alcance, parece, mundial (GONÇALVES, 2006; RIGHETTI, 2004; PORTO e RÉGNIER, 2003).

No caso específico do ensino abordado, é bastante claro que houve, e até o momento há, uma preferência do governo pelo investimento na educação básica em detrimento do superior, deixando este nas mãos de atores privados. A questão central aí, é que não se tratam de atores homogêneos, com sérias preocupações com a qualidade - são, com base nas entrevistas feitas, empresas que buscam atender demandas na medida em que estas possam ser atendidas; ou seja, quanto menores são as expectativas do alunado, menores são os esforços qualitativos. 
Perto dos vestibulares, poucos mantenedores estão confiantes de que vão iniciar o ano de 2006 sem ociosidade, com relação candidato/vaga muito próxima de 1 ou mesmo inferior. De outro lado, não se sustentam mais esperanças, nem há tempo para aguardar o que o governo federal pode fazer pelas escolas, além das poucas medidas de caráter populista que vêm sendo implementadas, como o FIES, o Prouni e o sistema de cotas. (entrevista 2)

O ensino superior privado carece de proposta pedagógica efetiva; e os mecanismos estatais de regulação e controle são, na prática, ineficazes. As mudanças institucionais ocorridas são de ordem isomórfica: coercitivas quanto aos requisitos mínimos exigidos pela legislação pertinente e instrumentos de avaliação; normativas, portanto de nível semelhante, posto que em sua maioria compartilha membros do corpo docente, o que introduz padrões de ensino qualitativamente isomórficos; e miméticas na competição, o que não resulta em difusão de excelência, mas de cópia, resultando em legitimidade na qual torna-se difícil distinguir escolas melhores e piores, exceto nos casos em que sejam significativamente um ou outro.

Por fim, é fato que o contorno institucional, bem como sua lógica de formação, popularizou o ensino superior, o que traz saldo líquido positivo no acúmulo de conhecimentos na sociedade. Porém, ainda é contestável em que patamar isso vem sendo feito, produzindo, grosso modo, acadêmicos e profissionais de qualidade inferior à formação pública, o que tem gerado redução da média de renda das categorias profissionais.

\section{REFERÊNCIAS}

BERGER, P. L.; LUCKMANN, T. The social construction of reality: a treatise in the sociology of knowledge. New York: Doubleday Anchor Book, 1967.

BRASIL. Ministério do Planejamento, Orçamento e Gestão. Plano Diretor de Reforma do Estado. Brasília, nov. 1995. Disponível em: <http://www.planejamento.gov.br/ gestao/conteudo/publicacoes/publicacoes.htm> Acesso em: 11/10/2005. 
BRESSER PEREIRA, L. C. Crise econômica e reforma do Estado no Brasil: para uma nova interpretação da América Latina. São Paulo: Editora 34, 1996.

. Estratégia e estrutura para um novo Estado. Revista de Economia Política, São Paulo, v. 17, n. 3, jul./set. 1997.

CANDELORI, R. Atualidades: o Consenso de Washington e o neoliberalismo. Folha Online, 14/11/2002. Disponível em: <http://www1.folha.uol.com.br/folha/educação/ ult305ul11503.shtml $>$ Acesso em: 10/10/2005.

CASTOR, B. V. J. O Brasil não é para amadores: Estado, governo e burocracia na terra do jeitinho. 2. ed. Curitiba: Travessa dos Editores, 2004.

COELHO, M. F. P. Reforma da educação e Prouni. Brasília: Ministério da Educação/ Assessoria de Comunicação Social, 2004. p. 1-2.

DIMAGGIO, P. J.; POWELL, W. W. The iron cage revisited: institutional isomorphism and collective rationality in organizational fields. Administrative Science Review, v. 48 , n. 2, p. $147-169,1983$.

DINIZ, E. Crise, reforma do Estado e governabilidade: Brasil, 1985-95. Rio de Janeiro: Fundação Getulio Vargas, 1997.

DUPAS, G. A lógica econômica global e a revisão do Welfare State: a urgência de um novo pacto. In: BRESSER PEREIRA, L. C.; WILHEIM, Jorge; SOLA, Lourdes (Org.). Sociedade e Estado em transformação. São Paulo: UNESP; Brasília: ENAP, 1999.

EMIRBAYER, M.; GOODWIN, J. Network analysis, culture, and the problem of agency. American Journal of Sociology, v. 66, n. 6, p. 1411-1454, 1994.

FIORI, J. L. Reforma ou sucata: o dilema estratégico do setor público brasileiro. São Paulo, IESP-FUNDAP, v. 6, n. 4, nov. 1991. Texto para discussão.

GAVIÃO, M. O fim dos privilégios. Brasília: Ministério da Educação/Assessoria de Comunicação Social, 2005. p. 1-3.

GAZZOLA, A. L. Instituições terão mais autonomia. O Tempo, 5 jun. 2006. Entrevista a Rodrigo Clemente.

GIAMBIAGI, F.; MOREIRA, M. M. Políticas neoliberais? Mas o que é o neoliberalismo? Revista do BNDES, Rio de Janeiro, v. 7, n. 13, p. 171-190, 2000.

GONÇALVES, S. Ambientes institucional e técnico e esquemas interpretativos: o caso da Companhia Paranaense de Energia - COPEL. Dissertação (Mestrado em Administração) - CEPPAD, Universidade Federal do Paraná, Curitiba, 1998. 
. Formação e dinâmica de campos organizacionais. Tese (Doutorado em Administração) - EAESP, Fundação Getulio Vargas, São Paulo, 2006.

HOFMAN, A. A. Economic Growth and Performance in Latin América Before and After the 'Lost Decade'. CEPAL, 1999. Mimeo.

MACHADO-DA-SILVA, C. L.; FONSECA, V. S. Homogeneização e diversidade organizacional. In: ENCONTRO ANUAL DA ANPAD, 17., Salvador, 1993. Anais... Salvador: ANPAD, 1993. v. 8, p. 147-159.

. Competitividade organizacional: uma tentativa de reconstrução analítica. Organizações e Sociedade, Salvador, v. 4, n. 7, p. 97-114, dez. 1996.

MANTEGA, G. O modelo econômico brasileiro dos anos 90. São Paulo: Fundação Getulio Vargas/Núcleo de Pesquisas e Publicações, 2001a. (Série Relatórios de Pesquisa, n. 11).

- O programa de privatizações brasileiro e a sua repercussão na dinâmica econômica. São Paulo: Núcleo de Pesquisas e Publicações/Fundação Getulio Vargas, 2001b. (Série Relatórios de Pesquisa, n. 53).

MEYER, J. W.; ROWAN, B. Institutionalized organizations: formal structure as myth and ceremony. In: MEYER, J. W.; SCOTT, W. R. (Ed.). Organizational environments: ritual and rationality. London: Sage, 1983.

PINTO, J. E. N. Os dois C das PPPs. Mundo Jurídico, 3/5/2004. Disponível em: <www. mundojuridico.adv.br>. Acesso em: 27/9/2005.

PORTO, C.; RÉGNIER, K. O ensino superior no mundo e no Brasil: condicionantes: tendências e cenários para o horizonte 2003-2025. Disponível em: $<$ http://portal.mec. gov.br/sesu/arquivos2003 $>$. Acesso em: 30/6/2005.

RIGHETTI, S. Crescimento de instituições privadas de ensino superior é fenômeno mundial. Disponível em: <http://www.comciencia.br/reportagens/2004/09/07.shtml $>$. Acesso em: 27/9/2005.

SACHS, I. O Estado e os parceiros sociais: negociando um pacto de desenvolvimento. In: BRESSER PEREIRA, L. C.; WILHEIM, J.; SOLA, L. (Org.). Sociedade e Estado em transformação. São Paulo: UNESP; Brasília: ENAP, 1999.

SAMPAIO, H. Ensino superior no Brasil. São Paulo: HUCITEC, 2000.

SUNKEL, O. Globalização, neoliberalismo e reforma do Estado. In: BRESSER PEREIRA, L. C.; WILHEIM, Jorge; SOLA, Lourdes. (Org.). Sociedade e Estado em transformação. São Paulo: UNESP; Brasília: ENAP, 1999. 
TRINDADE, H. Reforma e avaliação da educação superior. Brasília: Ministério da Educação/Assessoria de Comunicação Social, 2004. p. 1-2.

WILLIAMSON, J. Reformas políticas na América Latina na década de 80. Revista de Economia Política, v. 12, n. 1 (45), p. 43-49, jan./mar. 1992.

WORLD BANK ANNUAL REPORT. The third wave of privatization, p. 1-28. Sept. 1995.

Texto recebido em 06 nov. 2007

Texto aprovado em 17 dez. 2007 